\title{
Francisco de Velasco y los catalanes. Sitio y capitulación de Barcelona, $1705^{*}$
}

\section{Julio Luis Arroyo Vozmediano \\ UNED}

\author{
Day after day, alone on the hill, \\ the man with the foolish grin is keeping perfectly still. \\ But nobody wants to know him, they can see that he's just a fool, \\ and he never gives an answer...
}

The Beatles: "The Fool on the Hill", Magical Mistery Tour, Londres, 1967, Parlophone.

RESUMEN: La capitulación de Barcelona de 1705 fue un episodio de gran relevancia en la Guerra de Sucesión. El presente trabajo trata las alternativas, la decisión y los preparativos de la operación aliada, de la defensa de la ciudad condal por el virrey de Cataluña Francisco de Velasco, del desarrollo de las operaciones militares, y de la actitud de los catalanes durante el sitio. Para su elaboración se ha acudido a diversos archivos españoles y británicos. Las conclusiones a las que llega son que el elemento determinante, por encima de todos los demás factores que intervinieron en el desenlace final, fue la pobre actuación del virrey Velasco durante el asedio de Barcelona.

Palabras Clave: Guerra de Sucesión española; Peterborough; Francisco de Velasco; Barcelona; Cataluña; España; Inglaterra.

* Este trabajo ha sido elaborado gracias a la ayuda de los proyectos financiados por el Ministerio de Economía y Competitividad «Comercio y Finanzas Internacionales en una España en Transición, 1680-1721», (HAR2011-25907) y «Conservación de la Monarquía y Equilibrio Europeo entre los siglos XVII y XVIII», (HAR 2012-37560-C02-01). 
Francisco de Velasco and the Catalans. The siege and capitulation of Barcelona, 1705

ABSTRACT: The capitulation of Barcelona in 1705 was an episode of great importance in the War of Succession. This paper focus on the alternatives, the decision making and the preparation of the allied operation, the defense of Barcelona by the Catalonia's Viceroy Francisco de Velasco, the development of military operations, and the attitude of the Catalans during the siege. It's based on direct sources collected in Spanish and British archives. The conclusions reached are that the determining element, above all the factors that involved the end of the episode, was the bad Velasco's performance during the siege.

KEY WORDS: War of Spanish Succession; Peterborough; Francisco de Velasco; Barcelona; Catalonia; Spain; England.

En el verano de 1705 se produce un hecho transcendental en la Guerra de Sucesión: el ataque y la capitulación de Barcelona ante un ejército comandado por el conde de Peterborough, al que acompañaba el archiduque Carlos de Austria. Tras él, se produce el reconocimiento del pretendiente como sucesor de Carlos II y, en poco tiempo, la práctica totalidad de los territorios peninsulares de la Corona de Aragón caen bajo el control aliado.

Un asedio de Barcelona no era inusual en aquellos tiempos. Entre 1697 y 1714 se produjeron cinco $^{1}$. En el primero, en 1697, durante la guerra de los Nueve Años, Francia consigue tomarla. Luis XIV, con generosidad calculada, habría de emplear su devolución como una baza en la cuestión sucesoria. El segundo, en 1704, se salda con el fracaso de una expedición aliada que, en su viaje de retorno, captura Gibraltar. El tercero es el que vamos a tratar. En 1706 Felipe V, con un ejército franco-español de 30.000 hombres, no consigue su reconquista. El último, en 1714, aunque logró su objetivo, nos resistimos a calificarlo de éxito por su cruel desenlace. Fue el único que no terminó en capitulación, ya que las autoridades catalanas, huérfanas del apoyo aliado tras Utrecht, se negaron a rendirse incondicionalmente. El 11 de septiembre las tropas franco-españolas de Berwick culminaban el asalto de la ciudad condal luchando, calle por calle, hasta aplastar toda resistencia.

Todas y cada una de las tentativas revistieron una importancia singular. Pero fue la captura de 1705 la que tuvo consecuencias de un mayor calado, ya que constituyó el desencadenante de la pérdida para Felipe V de la Corona de Aragón. El escenario peninsular, relativamente tranquilo, se había centrado en la contención de los aliados en la frontera con Portugal, incluso con una inva-

1 Existe una monografía que trata conjuntamente los cinco asedios: TORRAS I RIBÉ, 1999. 
sión del país en 1704. Tras la capitulación se abría un nuevo frente que habría de concentrar todo el esfuerzo de guerra español, con un importante apoyo francés, en un momento en el que, tras Blenheim, más necesario resultaba en otros escenarios como Italia o Flandes. Pero esos recursos hubieron de ser destinados a la propia España donde se llega a perder Madrid durante unos meses en 1706. Asimismo, el reconocimiento del archiduque significó otorgar a su pretensión una sólida base territorial y jurídica; la articulación de un proyecto político - el austracismo - en su derredor; supuso también la excusa de la integración unitaria de los reinos peninsulares por la Nueva Planta, y transformar lo que era un conflicto internacional en una guerra civil entre españoles ${ }^{2}$.

Los sucesos de 1705 han sido tratados abundantemente por la historiografía pero quizá se ha abusado del recurso a las fuentes indirectas y carecemos de un relato pormenorizado de cómo se produjeron los hechos. Además en ocasiones se ha partido de ideas preconcebidas que han pecado de lo que Marcel Proust prevenía respecto de las convicciones que crean evidencias. A veces, por fin, se han forzado las consecuencias del hecho, para presentarlas como causas. Nuestra idea por tanto ha sido intentar aclarar la forma en la que se produjo la capitulación, acabando con ella la exposición.

Este artículo está basado, en lo fundamental, en fuentes directas recogidas en la British Library y The National Archives de Londres, el Archivo Histórico Nacional de Madrid y el de la Ciudad de Barcelona. Dichas fuentes se han complementado con las noticias publicadas en Londres durante las semanas del asedio ${ }^{3}$. Los aspectos sobre los que hemos querido incidir especialmente son los siguientes: cuál fue la actitud real de los catalanes ante la expedición aliada, cómo se gestó ésta y cuáles eran sus objetivos, de qué forma se produjo la captura militar y, por último, revisaremos el desempeño de Velasco durante la defensa.

\section{LOS MESES PREVIOS}

El archiduque Carlos había desembarcado en Lisboa en 1704 con un importante contingente aliado, iniciando ataques contra los dominios de Felipe $\mathrm{V}$. Se intenta la captura de Barcelona donde parecía encontrarse un importante apoyo. Pero el ataque, realizado en mayo, fracasa ${ }^{4}$. Al regreso, en agosto,

2 Para la figura del archiduque y sus apoyos en España, LEÓN SANZ, 2003.

3 Todos los periódicos citados están disponibles en la colección Burney de la British Library.

4 Para este episodio, y en general para todo el contexto, resulta imprescindible la reciente monografía de ALBAREDA, 2010:142-148 y VOLTES BOU, 1963, II: 28-29. Sobre la actitud de las instituciones catalanas en este primer intento de toma de Barcelona, vid ALABRÚS, 2001:150-154. 
se produce la toma de Gibraltar en nombre del archiduque pero permaneciendo bajo administración inglesa y proporcionando una base desde la cual estorbar el comercio americano de Cádiz y acceso abierto al Mediterráneo ${ }^{5}$. Peores noticias para las dos coronas llegaban del frente alemán. La batalla de Blenheim suponía el fin de largos años de primacía de las armas francesas en los campos de batalla de Europa y complicaba el pronóstico de la guerra en el norte 6 . Mientras se intenta recuperar Gibraltar, se produce una invasión de los aliados en Extremadura, donde asedian Badajoz en agosto. Aunque Tessé lograba en octubre rechazar las tropas aliadas hacia Portugal, la situación se iba deteriorando cada vez más para los intereses borbónicos.

En enero de 1704, Francisco de Velasco prestaba juramento como virrey de Cataluña. No se puede decir que tuviera un buen estreno en su magistratura, en pocos meses su falta de tacto y sus maneras autoritarias le habían granjeado enfrentamientos con las autoridades municipales, el tribunal de contrafecciones o la propia iglesia catalana ${ }^{7}$. El intento aliado de mayo y la represión posterior desencadenada por Velasco, con escasa altura de miras y con una intensidad que no parecía justificada por el poco apoyo que obtuvo aquél, parece que logró más el resultado de fomentar la causa aliada que el de controlar la desafección existente ${ }^{8}$.

Dadas dicha tentativa, la posesión de Gibraltar y la existencia de conspiradores en Barcelona, ésta se convierte en un punto sensible para la seguridad de la monarquía. Lógicamente deben tomarse precauciones ante cualquier contingencia, como informa Velasco en enero de 1705:

...para resguardar este principado de los riesgos a que le tiene expuesto su desprevención, tan observada de los enemigos de esta monarquía, como individualmente participada por la obstinada infidelidad de estos naturales 9 .

En la misma carta agradece el próximo envío de refuerzos procedentes de Milán y Nápoles, y su conformidad con las instrucciones sobre reforzar Montjuic, aunque manifiesta la carencia de los medios necesarios para la defensa. Efectivamente, se realiza un esfuerzo en ella, fundamentalmente con

5 Respecto al interés británico en la penetración en el Mediterráneo, ver MARTÍNEZ RUIZ, 65/221, (Madrid, 2005):1043-1062.

6 Tras una marcha arriesgada y espectacular por el corazón de Europa, Marlborough logra reunir sus tropas con las de Eugenio de Saboya y juntos, en agosto de 1704, infringir una durísima derrota para Francia: alrededor de 40.000 bajas y la ocupación de Baviera, ver HATTENDORF, 5/1, (Londres, 1983):3-19.

7 ALBAREDA, 1993:128; VOLTES BOU, 1963, II:8-11.

8 VOLTES BOU, 1963, II:11; ALBAREDA, 1993:128; MARTÍ, 2008:123:132

9 Archivo Histórico Nacional (AHN), Estado 272/29, Carta del virrey Velasco al marqués de Ribas, 28/I/1705. 
recursos humanos y materiales de Italia $^{10}$. Pero son tiempos difíciles. A menudo lo importante cede paso a lo urgente y desde el Principado se debe colaborar con otros lugares. Así Barcelona ayuda a la defensa de Mahón, Ciudad Rodrigo, otras partes de Cataluña o a las operaciones en Gibraltar ${ }^{11}$. El virrey atiende las peticiones pero «representa la falta de Infantería con que se halla y la poca con que quedara para guarnecer a Monjuy y cubrir los puertos» ${ }^{12}$.

Resultaba notorio el peligro, grave e inminente, de una operación naval anglo-holandesa, perfectamente conocido por Velasco y participado repetidamente a sus superiores desde bastantes meses antes del ataque,

como el tiempo esta tan adelantado, y las repetidas instancias que los que tramaron la conspiración antecedente hacen a nuestros enemigos, no atrasaran el apresto de la Grande Armada que las gacetas de todas partes dicen se forma para venir con ella sobre este principado ${ }^{13}$.

E incluso con detalle de las fuerzas que se esperan, reafirmándose en la urgente necesidad de medios de defensa:

y cada día se aumentan los justos recelos con que se debe vivir de esta depravada nación, mayormente con las noticias que llegan del Norte del grande armamento de 95 navíos de línea que se hace en Inglaterra y Holanda y que sin disimulo alguno se publica en aquellas partes, es para apoderarse de este principado ${ }^{14}$.

Poco antes de la toma de Barcelona, en junio, dos enviados catalanes se reúnen en Génova con Mitford Crowe, un comerciante de aguardiente que había residido en Reus, y que actuaba de ministro plenipotenciario de la reina Ana $^{15}$. Los catalanes eran Antoni de Peguera y Domènech Perera, miembros

10 AHN Estado, 272/59, 10/III/1705 y 272/18, 22 /IV/1705. Ambas sobre el progreso de las obras de fortificación de Montjuic; 272/12, Velasco a Mejorada, 15/IV/1705, informa del recibo de cobre procedente de Italia, con el que se habían fundido varias culebrinas destinadas al refuerzo de Montjuic.

11 AHN Estado, 272/13, Velasco a Mejorada, 18/IV/1705, informa del envío al castillo de Mahón de 106 hombres para su refuerzo; 272/16. Velasco remite enterado y conforme a la instrucción de que el regimiento de la guardia de Italia pase desmontado a Ciudad Rodrigo y de que se utilicen los caballos para completar otros regimientos, 1/IV/1705; 272/4, Velasco da cuenta a Mejorada de haber enviado refuerzos a Rosas y a Tarragona, 22/IV/1705; 272/20, Velasco a Mejorada, 15/IV/1705. Se había remitido desde Tortosa una batería y pertrechos para el sitio de Gibraltar. 272/73, 27/II/ 1705 y 272/82, 10 /III/1705, ambas sobre el envío y recepción de 18 cañones de bronce. 272/61, 10/III/1705, sobre una batería para Málaga.

12 AHN Estado, 272/19, Velasco a Mejorada, 15/IV 1705.

13 AHN Estado, 272/29, Velasco a Ribas, 28/I/1705.

14 AHN Estado, 272, Velasco a Ribas, 15/I/ 1705.

15 El detalle sobre la gestación del pacto, en ALABRÚS, 2001:154-157. 
de los «vigatans», un núcleo sedicioso de la comarca de Vic ${ }^{16}$. Cerraron un acuerdo con los ingleses por el que se comprometían a facilitar su desembarco y la proclamación del archiduque como rey, arrogándose una representación de Cataluña de la que carecían ${ }^{17}$.

Dicho esto, las evidencias demuestran la existencia de conspiradores en los meses previos a la conquista, aunque calificar a estos grupos de austracismo catalán, antes de 1705, peca, en nuestra opinión, de extemporaneidad. Naturalmente, según la definición que demos de Austracismo ${ }^{18}$. Antes de la toma de Barcelona, la pretensión del archiduque es una opción dinástica, no un proyecto político. Los nombres propios que conocemos -Vilana Perlas, Durán, Feliú de la Penya, Dalmases, Arnold Jäger- aparecen relacionados con los intercambios comerciales con las potencias marítimas interrumpidos por la guerra y el cambio dinástico, y mantenían contactos con el antiguo virrey Darmstad $^{19}$.

Gracias a la política internacional del reinado de Carlos II se había producido un crecimiento de las exportaciones, propiciado por el bloqueo sobre las mercancías francesas, de la que se va a beneficiar Cataluña mediante el comercio con las potencias marítimas. La expansión se fundamentaba en el comercio del aguardiente, vino y frutos secos. En contraprestación, se produce una lucrativa actividad importadora, fundamentalmente textiles ingleses y

16 Sobre el alzamiento de los vigatans, ver ALBAREDA, 1993:171-186; 2010:174-177 y VOLTES BOU, 1963 Tomo II: 39-43.

17 Independientemente de que pudieran ser hipotéticamente representativos del estado de opinión generalizado en el Principado, no gozaban de ningún título jurídico de representación. Respecto a este tema, ver GARCIA FUERTES, 4/17 (Madrid, 2004):150, «La escasa relevancia de las personas implicadas en el Pacto de Génova no concuerda con la trascendencia del mismo, por lo que tal vez detrás de esos hombres se ocultaban otros más importantes, pero más temerosos en caso de fracaso». Bien pudiera ser, pero no deja de ser un tal vez detrás de una evidencia patente: la irrelevancia política de los firmantes.

18 Así en el sentido dado por Jon Arrieta, si austracismo se corresponde con los partidarios de la sucesión del archiduque Carlos es claro que existe antes de 1705, pero si incluimos en la definición los matices aportados posteriormente por él de que el movimiento se configura por su visión de la estructura de la monarquía, es cuando dudamos de una existencia definida antes de 1705, ARRIETA, 2004 II: 247 y 2002:177-216. En este sentido, estamos de acuerdo con Ricardo García Cárcel quien opina que se configura «a partir del poder militar que se atribuye a los aliados», atribución que culmina, precisamente, con la toma de Barcelona, GARCÍA CÁRCEL, 2004: XXVIII.

19 La existencia de intereses comerciales se refiere tanto directamente a los obtenidos del tráfico mercantil como indirectamente a través de la actividad profesional como, por ejemplo, del notario Vilana Perlas. Para el virreinato catalán de Darmstadt, ver RAGON I CARDONER, 2 (Barcelona, 1984):263-272. También TORRAS I RIBÉ, 264 (Barcelona, 2001):23-31. Como enlace con los austracistas catalanes e instigador de su levantamiento, vid ALBAREDA, 2010:138-144. 
salazones de pescado ${ }^{20}$. Ambas actividades generan un importante beneficio que propiciará la emergencia y el fortalecimiento de una activa burguesía que va a conseguir ganar peso social y político ${ }^{21}$. Este comercio será dirigido desde Barcelona, que adquiere una pujanza notable conforme avanza y termina el siglo $^{22}$. Con la nueva dinastía se produce una modificación sustancial de la situación: los productos catalanes no se van a beneficiar de la exclusión de los franceses, sino que van a tener que competir con ellos, dentro y fuera de la Monarquía. Además, a partir del 11 de septiembre de 1701, se había prohibido el comercio con los aliados, acabando con estos negocios.

Identificándose con dichos grupos tendríamos al núcleo duro de conspiradores antiborbónicos, los vigatans y los celantes. Integrarían el mismo los mercaderes y hombres de negocios interesados en dicho comercio ${ }^{23}$. También las comarcas donde prendió la rebelión, la Plana de Vic, la Marina, Tarragona, eran las regiones productoras perjudicadas. El cambio dinástico suponía una amenaza grave a sus intereses, por lo que se enfrentan al mismo, buscando, mediante la alternativa austriaca, la restauración de la situación anterior. Esta restauración representaría el núcleo de lo que el profesor Albareda llama el proyecto económico del austracismo ${ }^{24}$.

Efectivamente, dicho proyecto económico se encontraba encuadrado dentro de una superestructura ideológica en el que el constitucionalismo catalán y el pactismo centraban su discurso, construido en textos de la época como los

20 VALLS JUNYENT, 2001:71-72.

21 ALBAREDA, 2010:128.

22 Durante el siglo XVII Barcelona se convierte en el centro director de una zona -Baix Llobregat, Maresme, Vallés, Anoia, Bages, Garraf, Penedés- cada vez más integrada económicamente estableciéndose como una verdadera metrópoli catalana, ver GARCÍA ESPUCHE, 15 (Barcelona, 1997):291-292.

23 “El Principat ha agafat el tren de la recuperació econòmica, guiat per l'exemple que representen Anglaterra i les Províncies Unides (el mirall holandès). Als anys vuitanta del segle XVII, Narcís Feliu de la Penya recull aquestes nocions de canvi econòmic, un canvi que és a les mans del sector de la burgesia mercantil barcelonina i del Maresme. Una burgesia que vol participar en el comerç internacional, que té productes exportables (l'aiguardent, el més destacat), que vol aquell tros del pastís americà que sempre se li ha negat, que vol crear companyies comercials; però que alhora es troba indefensa davant la feroç competencia dels productes tèxtils francesos, que vol una protecció del seu mercat davant la presència dels productes francesos", GONZÁLEZ CAMAÑO, 23 (Barcelona, 2003): 295-324.

24 «El programa econòmic solament podia esdevenir realitat mitjançant els ressorts que oferia el sistema constitucional, que havia de proporcionar suport a la producció pròpia enfront de les manufactures estrangeres, assenyaladament franceses, i a l'exportació d'aiguardent. Una argumentació que trobem al Político Discurso de Feliu de la Penya, el qual es fa ressò de les demandes dels prohoms dels gremis tèxtils que parlen de la crisi econòmica a causa de la lliure entrada de robes, la disminució d'ingressos perquè no paguen drets $[\ldots] \mathrm{i}$ on les Constitucions de Catalunya [són] invocades com a instrument econòmic»", tomado de ALBAREDA, 7 (Barcelona, 2002):27. 
Anales de Feliú de la Penya o las Narraciones Históricas de Castellví, pero que son posteriores a la caída de Barcelona y pecan de una visión un tanto determinista. La existencia de tensiones en el principado con las autoridades de la Corona a cuenta de los fueros y libertades se dieron efectivamente durante el virreinato de Velasco, pero también antes y después de él, inclusive durante el gobierno del archiduque ${ }^{25}$. Y tensiones parecidas se pueden encontrar en la propia Inglaterra con la actividad política del New Country Party durante el reinado de Guillermo III ${ }^{26}$.

En nuestra opinión es con la toma de Barcelona y el dominio de la Corona de Aragón por los aliados cuando se constituye el movimiento donde encuadrar dichos elementos políticos y económicos, y cuando se puede, con propiedad, hablar de austracismo. Antes existe un núcleo de inconformistas catalanes, y otros grupos como los tenedores de censos o la nobleza titulada castellana, que se sienten preteridos por la nueva dinastía ${ }^{27}$. Todos ellos, desde su descontento, proporcionan una base social y conformarán el discurso político del archiduque.

Y ¿en qué proyecto político se concretaban las inquietudes e intereses del grupo que encabeza la rebelión contra la autoridad de Felipe V? Si nos atenemos a la redacción de las cláusulas del Pacto de Génova de 1705, llama poderosamente la atención la octava. Con frecuencia, se hace referencia a esta estipulación resumiéndola así: «los catalanes se comprometen a reconocer como rey a Carlos III». Nótese que con tal redacción, es más una concesión que la solicitud de restitución de un rey legítimo. Parece, a su vista, que los objetivos políticos perseguidos respondían al deseo de una determinada oligarquía de garantizar su propia supervivencia política y posición comercial, que ven peligrar en la situación creada por el cambio dinástico. Desde este punto de vista, la construcción de la posición política catalana no es fruto del compromiso con la España de los Austrias, sino de la búsqueda de un camino propio en defensa de unos determinados intereses ${ }^{28}$.

25 LEÓN SANZ 2009: 19 y 181; MARTÍ 2008:164-168.

26 Se pueden establecer un claro paralelo entre el grupo de los celantes de las cortes de 1701-1702 y el New Country de los parlamentos de Guillermo. Tienen en común su desconfianza en que el poder de la Corona pudiera suponer una amenaza a las libertades tradicionales, su aversión a la presencia de tropas o incluso la existencia de un programa económico propio. Sobre las cortes catalanas, VOLTES BOU 1963: 6-7; respecto a Inglaterra, DOWNIE, 91/358 (Oxford, 1976):33-51 y RUBINI, 5/337 (Oxford, 1970): 693-714.

27 GARCÍA-BADELL, 15 (Madrid, 2008):125-126; LEÓN SANZ y SÁNCHEZ BELÉN, 21 (Madrid, 1998):127-175.

28 ALBAREDA, 7 (Barcelona, 2002):28. Así lo expresa el profesor Albareda: «Aquestes eren, essencialment, les raons de fons que van motivar l'aposta dels austriacistes. El rei pel qual lluitaven, Carles III, l'arxiduc, en constituïa el pretext. Es tractava, de fet, del candidat promogut per les potències marítimes (i l'Imperi, naturalment), el suport de les quals, plasmat 
En estos meses Velasco escribe repetidamente a Madrid, preocupado por la existencia de una conjura. En abril solicita el traslado desde Mahón a Meli1la de dos conspiradores: Joseph Roncal y Juan Cassas, a quienes se les había interceptado correspondencia con Viena y que, significativamente, califica de hombres de Darmstadt ${ }^{29}$. También en abril, comunica las disposiciones que ha tomado por si pasara a Cataluña el conde de Cifuentes, en ese momento tratando de sublevar Aragón tras intentarlo en América ${ }^{30}$. Un par de meses antes, Velasco había escrito que «...son infinitos los naturales de esta provincia que pasan por mar a Gibraltar para conducirse desde aquella plaza a el reino de Portugal y que de este vuelven algunos a esta provincia con cartas y noticias muy perjudiciales» ${ }^{31}$, manifestando que había dado órdenes de no permitir el embarque sin tener noticia cierta del destino. La conspiración existía, naturalmente, pero una cuestión es que hubiera más o menos conspiradores, y otra cosa, muy distinta, es hablar de una sublevación general de Cataluña. Precisamente de cómo se desarrollaron los hechos aquí tratados, podremos sacar algunas conclusiones que nos permitan calibrar correctamente la amplitud e intensidad del apoyo catalán a la causa aliada.

\section{Mientras TANTO, EN Lisboa}

Harto de la indecisión con que se había encontrado en la corte de Lisboa, llevado quizá de su carácter, Peterborough decidió zarpar ${ }^{32}$. Sus órdenes eran

en el pacte de Gènova de 1705, signat entre el comerciant d'aiguardents establert a Reus Mitford Crowe, en nom de la reina Anna d'Anglaterra, i una representació d'austriacistes catalans, havia de fer possible la materialització del programa que hem esbossat».

29 AHN Estado, 272/23, Velasco a Mejorada, 22/IV/1705.

30 AHN Estado, 272/17, Velasco a Mejorada, 1/IV/1705.

31 AHN Estado, 272/71, Velasco a Mejorada, 27/II/1705.

32 «Llegó en esto de Inglaterra a los aliados un refuerzo de hasta quince mil hombres, mandados por Juan Mordaunt, conde de Peterborough, singular personage; de talento extraordinario, pero extravagante; de poca piedad y religiosidad para inglés; valiente, inquieto, inconstante, poco sesudo; tory, y sin embargo, muy celoso del buen éxito de aquella guerra, poco grata a los de su partido; en suma hombre de gran mérito, pero obscurecido por su superior extravagancia; a propósito como quien más para guerrear al frente de partidas sueltas ó de segundo en el mando, ocasiones en que sirve de más un arrojo temerario que un valor prudente y juicioso; bueno con todo en alto grado para empresas que piden ímpetu en la ejecución y feliz inventiva en acometerlas y llevarlas a cabo», en ALCALÁ GALIANO, 1844, V:194, se ha utilizado el volumen de la British Library (en adelante BL), cuya referencia es BL 1323.c.15. Methuen abunda en esta impresión en sus cartas a Londres, así, por ejemplo, en 22/VI/1705 escribe al secretario de Estado sir Charles Hedges "My Lord Peterborouw notwithstanding his impatiente...", en The National Archives (TNA) State Papers (SP) $89 / 18 / 263 \mathrm{v}$. 
amplias. Realmente debemos de considerar esto como una de las ventajas de la dirección política inglesa de la guerra. La reina Ana le había remitido unas órdenes que le otorgaban diversas opciones donde elegir; soportar desde el mar un asedio del duque de Saboya a Tolón, invadir Andalucía, atacar en Cataluña.

Sin embargo las negociaciones con los portugueses resultaron, cuando menos, muy penosas al conde. Desesperado de conseguir nada claro, después de haberlo intentado todo, interminables reuniones con los ministros portugueses, una entrevista con la reina viuda, soportado disensiones con los holandeses ${ }^{33}$. Ya que no puede hablarse de que existiera unanimidad en la elección del objetivo, la correspondencia diplomática inglesa sitúa al holandés Schonemberg en franco desacuerdo con la operación. «They are all (los portugueses) against the attempt in Catalonia, especially Schonemberg, the Ducht envoy», escribe el 24 de junio ${ }^{34}$.

Se puede cuestionar la importancia real del pacto de Génova en el desarrollo de los acontecimientos. Las instrucciones de la reina Ana a Peterborough están fechadas en el palacio de Sant James el 7 de mayo de 1705 (O.S) ${ }^{35}$. En ellas se hacía referencia ya al intento en Cataluña, si bien especificaban que habría de acometerse a la vuelta del primer objetivo, apoyar el ataque del duque de Saboya a Tolón. El 5 de junio, ante las alternativas, el secretario Hedges le expresa a Peterborough «but this is left an entirely to you, and you are to do therein as you judge best for Her $\mathrm{Ma}^{\text {sty }}$ service ${ }^{36}$. Pero es en el consejo de guerra celebrado en la residencia de Methuen el 28 de junio, cuando se toma la decisión unánime de atacar Barcelona ${ }^{37}$. El pacto de Génova fue firmado el 20 de junio, siendo improbable que fuera determinante en la decisión final. Además de los problemas -por la estrechez de fechas- para confirmar su conocimiento en la reunión, no se cita en sus actas. Dos aspectos parecen más determinantes:

33 TNA SP 89/18/275 Carta de John Methuen a Sir Charles Hedges. 24/VI/1705. Peterborough y él se han entrevistado con la reina viuda y esperan que ello contribuya a acelerar las cosas.

34 TNA SP, 94/75, Peterborough a Hedges, 24/VI/1705. También existen referencias en la correspondencia de Methuen, TNA SP 89/18/280-281, Methuen a Hedges, 22/VII/1705, informa del encuadramiento de la caballería "made to the satisfaction of all concerned despite Schonenberg's obstruction".

35 TNA SP, 94/75, instrucciones de la reina Ana para Peterborough y Shovell, 7/V/1705. En ellas se especifica la importancia del ataque a Tolón: "the execution of that service is preferably to any other", y que, una vez realizada dicha empresa, "you may return to Barcelona for putting in execution the other part of your instructions". Inglaterra no adoptó el calendario gregoriano hasta mediados del XVIII, corrigiendo el desfase de 11 días con el juliano. La documentación inglesa utiliza O.S. (Old Style) o N.S. (New Style) para diferenciar las fechas inglesa y continental.

36 TNA SP 94/75. Hedges a Peterborough. 5/VI/1705.

37 TNA SP, 94/75, consejo de guerra celebrado en casa de Methuen, Lisboa, 28/VI/1705. 
Las quejas sobre la falta de apoyos y compromiso por parte de Portugal en apoyo de la marcha sobre Andalucía, según se recoge en el acta:

is far short of what my Lord Gallway demanded, less tan which his Lordship thinks insufficient to answer the end proposed of marching thro Andalucia to Cadiz (...) and further observing that after conferring for above a fortnight with the Portuguese Ministers in order to obtain something positive in writing, for their concurring in some design in Catalonia, or against Cadiz, that nothing could be obtained from them... ${ }^{38}$.

Lo avanzado de la estación: tomando dicha decisión a finales de junio, la flota no se reunió y partió de Gibraltar hasta agosto. Afrontaba una larga travesía con barcos repletos de hombres, caballos e impedimenta. El fin de verano es temporada de lluvias y tormentas en el mediterráneo occidental y la demora aumentaba el riesgo de la navegación. Al estar el norte de Italia y el duque de Saboya considerablemente más lejos, la opción de atacar Barcelona resultaba más segura.

Se deben destacar los riesgos y el costo exorbitante de una operación de este tipo, capaz de tensionar enormemente las finanzas públicas. Sólo el coste de la artillería que habría de acompañar a la expedición fue estimado por Stanhope en $50.272 £^{39}$. Otro aspecto es el pago a la compañía de catalanes, que además nos permite corroborar las informaciones de Velasco a Madrid. Methuen escribe a Londres comunicando el pago de 57.000 piezas de a $\mathrm{ocho}^{40}$. La suma de ambas cifras, siendo considerable, es sólo una fracción de los costes directos e indirectos de la expedición. La complicación logística también resultaba enorme. Las dificultades de transportar 12.000 hombres y 1.000 caballos no resultaban desdeñables y hay que añadir el resto de suministros, repuestos e impedimenta. Un memorial enviado por la oficina de suministros al secretario Hedges cuantifica en 504 toneladas sólo el embarque necesario para el viaje de Peterborough a Lisboa que la expedición a Barcelona superaría mucho ${ }^{41}$.

38 TNA SP, 94/75, consejo de guerra celebrado en casa de Methuen, Lisboa, 28/VI/1705.

39 TNA SP, 41/34/52. Informe de Stanhope sobre lo necesario para acompañar al ejército expedicionario a Cataluña. La partida más importante era la artillería, cifrada en $21.354 £$.

40 TNA SP, 89/18/278, recibo otorgado por el archiduque a Methuen atestiguando el pago de las 57.000 piezas de a ocho para la compañía de catalanes que iba a embarcar, Lisboa, 21/VII/1705. También hace referencia al mismo el 89/18/280-281, de Methuen a Hedges de 22/VII/1705 con la que envía el recibo. Antes, en junio, había informado de los pagos realizados, de los que esperaba reembolso, 89/18/262- 263, Methuen a Hedges, 22/VI/1705.

${ }^{4}$ Hemos traducido el nombre de la Board of Ordnance, oficina encargada de los suministros al Ejército y la Armada, durante los siglos modernos, bajo control parlamentario. Sobre este tema, resulta muy interesante la consulta de CLODE, 1869. TNA SP 41/34/24, Board of Ordnance a Hedges, 14/IV/1705, los comisionados les han prometido 504 toneladas de embarque para los oficiales y suministros de la expedición de Peterborough. Una relación 
Los riegos no eran sólo de carácter económico o material. Si los recursos son, por definición, escasos, la disponibilidad de tropas entrenadas y listas para combatir resultaba también problemática para los aliados, quienes habían tenido que recurrir repetidamente a la opción de subarrendar tropas a distintos príncipes $^{42}$. La misión de Peterborough tenía un carácter único; un fracaso debilitaría gravemente la capacidad de iniciativa aliada. Se eligiera el destino que fuera para la expedición, una prioridad debía ser asegurar la supervivencia del ejército. Un par de años más tarde se demostró esto. Tras la derrota en Almansa, sólo los éxitos en Italia y Flandes hicieron posible el traslado de tropas para reponer pérdidas, pero no estuvieron en condiciones de volver a tomar la iniciativa en la Península hasta 1710.

Por tanto las consecuencias de lo antedicho son que los aliados habían confiado a Stanhope un ejército, no demasiado numeroso, para que fuera empleado, según aparece en sus instrucciones «for carrying on any designs against the commons enemyes» ${ }^{43}$. La decisión de atacar Barcelona respondía a las circunstancias que enmarcaban el contexto en que fue tomada.

\section{Asalto y CAPItUlación de BARCElona}

La armada se concentra en Gibraltar a principios de agosto de 1705. Bajo el mando militar de Peterborough, el propio archiduque se une a la expedición. Debemos destacar también la importancia política de dos comandantes que integraban la expedición. El príncipe de Darmstadt había sido virrey de

pormenorizada, sin cuantificar económicamente, de todos los elementos necesarios en BL Stowe 324/15/142. También se puede seguir el rastro de los preparativos en numerosos documentos, por ejemplo: TNA SP 34/6, la Board of Ordnance a Hedges sobre el coste de las demandas de Peterborough, 10/IV/1705; 34/6, sobre los preparativos en los barcos para la expedición, 14/IV/1705; 41/34/23, sobre distintos suministros solicitados por Peterborough, 10/IV/1705.

42 BL Add 28945, fols. 105-108. 4/VI/1701. El Emperador trata de contratar unas tropas del rey de Dinamarca, en Sajonia, para la defensa de sus derechos en España. Fols. 115-118: Resumen de un tratado realizado por el rey de Inglaterra, el de Dinamarca y las Provincias Unidas, de 15/VI/1701. Inglaterra y las Provincias Unidas pagarán 300.000 coronas al año al rey de Dinamarca, a cambio éste enviará un contingente de 8.000 infantes, 1.000 dragones, 3.000 caballos y prestará asistencia naval, por un artículo secreto se compromete a armar 4.000 hombres más. En términos parecidos se inician acciones diplomáticas ante el rey de Prusia en BL Add 28945, fol. 223. Carta de Guillermo III invitando al rey de Prusia a unirse a la gran Alianza de 28/X/1701. Fol. 224, respuesta del rey de Prusia 5/XI/1701. Fols. 290-319, adhesión del rey de Prusia a la Gran Alianza, enero de 1702. También se intentaron otras iniciativas diplomáticas ante el elector de Hannover, fols. 227-228, 9/XI/1701; de Colonia, fols. 252-253, 18/XI/1701 y del Palatinado, fol. 260, 22/XI/1701, estas dos últimas, infructuosas.

43 TNA SP 94/75, Hedges a Peterborough, 5/VI/1705. 
Cataluña con Carlos II y mantenía contactos en el principado. También integraba la expedición James Stanhope, hijo del antiguo embajador en Madrid. La flota parte hacia el levante peninsular. Desembarca un contingente de tropas al mando de Juan Basset, que toma Altea y Denia y continúa la travesía. El 22 de agosto alcanzan y fondean frente a Barcelona, desembarcando en la desembocadura del Besós. A pesar del pacto de Génova, no se produce el alzamiento favorable y la situación se prolonga durante casi dos meses.

En Londres se publicaban las noticias de la llegada de la flota el 1 de septiembre (O.S), manejando como fuentes cartas recibidas de París y fechadas en 4 de septiembre (N.S) ${ }^{44}$. Se informaba de la llegada a Barcelona y el desembarco de 10.000 hombres a los que se habrían unido «by 4 or 5000 Malecontents». Los habitantes de Barcelona manifestaban su intención de declararse en favor de Carlos III, lo que había provocado que el virrey situara artillería en las calles, entre otras medidas ${ }^{45}$. Antes se tiene noticia, de la revuelta de los habitantes de Vic, de quienes dice que han tomado las armas en favor de Carlos III y que han matado a diversos franceses y agentes de Felipe $\mathrm{V}^{46}$. Esta información tiene una apreciable demora ya que también informan del paso del estrecho de la flota aliada. Sitúa el empuje de la revuelta hacia los puertos ubicados entre Girona y Palamós, y apuntan a la existencia de un núcleo de descontentos en Roses. De Velasco dicen que ha detenido a varias personas que mantenían correspondencia con Darmstadt.

Las noticias del avistamiento de la flota habían llegado a Barcelona el día 13 de agosto, cuando el consejo municipal, Consell del Cent, recibe información de Tortosa de que una considerable flota enemiga, 150 velas, se dirigía allí $^{47}$. El Consell ofrece su asistencia al virrey en todo lo necesario. El día 16 acuerdan el acopio de víveres y avituallamiento para el asedio, demostrando su compromiso con la Corona al día siguiente, aunque con alguna salvedad ${ }^{48}$.

44 Post Man, 1/IX/1705, $\mathrm{n}^{\mathrm{o}}$ 1443. London Gazette, 3/IX/1705, $\mathrm{n}^{\circ} 4155$, se hace eco de la misma noticia, pero recogiendo una horquilla de entre 2.000 y 5.000 para los sublevados unidos al contingente aliado; también recogido en Daily Courant, 7/IX/1705, $\mathrm{n}^{\circ} 1061$.

45 Daily Courant, 7/IX/1705, $\mathrm{n}^{\mathrm{0}} 1061$, sobre la detención por Velasco de algunos conspiradores.

46 Daily Courant, 24/VIII/1705, $\mathrm{n}^{\circ}$ 1049, citando la Leiden Gazette, sobre noticia fechada en París del 21/VIII/1705. Daily Courant, 25/VIII/1705, $\mathrm{n}^{\circ} 1050$, citando la gaceta de Bruselas, habla de 4 familias que habrían levantado a 400 hombres.

47 Archivo Histórico de la Ciudad de Barcelona. Consell del Cent. Registre de Deliberacions. Signatura 1B.II-214 (1704-1705), Rollo 153CC (En adelante AHCB CC, -todas referidas a la misma microficha-), fols. 259-262. Junta del 13/VIII/1705.

48 AHCB CC, 1B.II-214 (1704-1705), Rollo 153CC, fols. 263-264, junta del 16/VIII/1705. Fols. 264-267, junta del 17/8/1705. Deciden realizar todo lo necesario «per lo major servey del Rey Ne. Sr. (Deu lo g $^{\text {de }}$ y resguart, defensa y conservatio de esta capital baix lo suau y amable domini de sa Mag ${ }^{\text {tat }}$, com y tambe a premeditar y discorrer lo que ha aparegut podía y devria fer esta Ciutat en locas present que se trobe amenazada de la armada enemiga per lo major 
El 18 convoca una comisión delegada para todo lo relativo a la defensa, la Novena de Guerra, y se consignan 3.000 libras catalanas para gastos ${ }^{49}$.

El día 20 ofrecen la formación de la Coronela, la milicia ciudadana, y Velasco contesta que cuenta con tropas suficientes para cubrir murallas y fortificaciones, reservando tal posibilidad para caso de mayor urgencia ${ }^{50}$. El día siguiente el síndico de la ciudad visita al virrey, insistiendo en la formación de la milicia «para prevenir los disturbios y atajar los incendios que pudieran provocar los bombardeos de la escuadra enemiga», a lo que Velasco se vuelve a negar ${ }^{51}$. También se escribe a Felipe V para que «favorezca esta ciutat ab las mes promptes y efectivas providencias para poderse mantener en son Real y amable domini de Sa Magestat que es son major desitg $\rangle^{52}$.

Recapitulemos sobre la situación una vez producido el desembarco aliado. De una parte tenemos el ejército expedicionario, en torno a 10.000 hombres, cuentan con el dominio del mar y con la artillería de a bordo ${ }^{53}$. La caballería de que disponen es inferior en número a la de los defensores. No consiguen incomunicar la ciudad, manteniendo Velasco una frecuente correspondencia con el secretario de Guerra, Grimaldo, durante el asedio. Las tropas españolas sobrepasaban los 6000 infantes y los 1000 caballos $^{54}$. La fortaleza de Montjuic estaba guarnecida por tropas veteranas de napolitanos y se encontraban artilladas moderadamente las diversas posiciones en las murallas y en la fortificación.

Al ejército expedicionario se le había sumado alguna cantidad de catalanes sublevados que oscila, según las fuentes, entre 1000 y 5000. Nos parece más

desempenyo de la primera obigacio de dita present ciutat», aunque también acuerdan consultar si algún capítulo de las disposiciones del virrey atentaba contra sus privilegios o libertades.

49 AHCB CC, 1B.II-214 (1704-1705), Rollo 153CC, fols. 267-270, junta del 18/VIII/1705.

50 AHCB CC, 1B.II-214 (1704-1705), Rollo 153CC, fols. 270-272, junta del 20/VIII/1705.

51 AHCB CC, 1B.II-214 (1704-1705), Rollo 153CC, fols. 272-275, junta del 21/VIII/1705.

52 AHCB CC, 1B.II-214 (1704-1705), Rollo 153CC, fols. 272-275, junta del 21/VIII/1705.

53 No está clara la potencia de fuego aliada. Voltes Bou indica, citando documentación española, una cifra de entre 12 y 14.000 soldados aliados, entre los que se encontrarían dos escuadrones de caballería, reforzados por 2.100 infantes de marina y 52 cañones, VOLTES BOU, 1963:49. Los consejos de guerra no dan cifras sobre sus tropas, pero la prensa inglesa, habitualmente bien informada, da unas cifras algo inferiores, el Post Man, 1/IX/1705, no 1443 y la London Gazette, 3/IX/1705, $\mathrm{n}^{\circ} 4155$ hablan de un contingente de 10.000 soldados aliados en las primeras noticias del ataque. El Daily Courant, 18/IX/1705, $\mathrm{n}^{\circ} 1070$ cifraba en 8.000 el número de soldados aliados, distinguiendo los 4.000 marineros de la flota, y estimando en 500 los caballos "in condition to serve", estas cifras, publicadas dos semanas después, parecen bastante congruentes, además, con las cartas de Barcelona, AHN Estado 264: «los enemigos no tienen gente para atacar a Barcelona por que no son más de 8000 mil infantes y 400 caballos».

54 AHN Estado 264, «la guarnición de la plaza es muy numerosa de más de 6000 Infantes y 1000 caballos y que salían las partidas a tito de pistola de las líneas que los abastos están en grande abundancia y el ánimo es de perecer antes de rendirse». 
probable la primera cifra, recogida por el Daily Courant, por estar en congruencia con las cartas de Velasco a Madrid y, sobre todo, con las actas de los consejos de guerra aliados celebrados en el buque insignia Britannia ${ }^{55}$. Repetidamente la mayoría de los oficiales presentes se mostraban decepcionados por la falta del apoyo que esperaban y partidarios de levantar el campo y viajar al encuentro de Eugenio de Saboya. Las críticas se basan en el bajo número, compromiso e incluso fiabilidad de los que se les habían unido. Así en el consejo del día 27 de agosto se recoge:

but even by those, who, finding themselves desperate, by having join'd us, would in all Probability be very glad to make their Peace at Home, by assisting to destroy us ${ }^{56}$

o en el del día 8 de septiembre:

Eight Deputies from the Catalans did declare to the earl of Peterborouw and her $\mathrm{Maj}^{\text {ties }}$ envoy that they could no promise any number of men to work at our trenches and Batteries, or in every place where they Should be exposed to Fire, which they said could not be expected from indisciplined Country people ${ }^{57}$.

El ejemplar que acabamos de citar del Courant rebaja a 800 los campesinos de la plana de Vic unidos a los aliados y pone de manifiesto las muestras de lealtad a favor de Felipe V en Cataluña, con la captura de algunos soldados ingleses y rebeldes por migueletes leales. No parecen fiables las cifras de los sublevados, seguramente más de 800 , pero debían de estar lejos de los 5000 que estimaban las fuentes más optimistas ${ }^{58}$. Hay que pensar que en esos momentos existían grupos de insurrectos combatiendo en Lérida o en Tarragona y que no podría haberse reunido un gran grupo en Barcelona. Recordemos, además, que viajaba embarcada en la expedición la compañía de catalanes a la que se refería el embajador Methuen. Sumados a los que se habrían incorporado del país, podremos aventurar una cifra de en torno a dos o tres mil catalanes auxiliando al contingente aliado y que no sobrepasarían hasta, por lo menos, la caída de Montjuic. No obstante, se proporcionan elementos de convicción suficientes para poder descartar un levantamiento general en estos momentos. Estas cifras, incluso algo superiores, no bastaban para realizar un

55 Daily Courant, 18/IX/1705, $\mathrm{n}^{\circ} 1070$.

56 TNA SP 94/75, consejo de guerra en el Britannia, 27/VIII/1705 (N.S.).

57 TNA SP 94/75, consejo de guerra en el Britannia, 8/IX/1705 (N.S.).

58 Velasco se muestra también escéptico sobre la existencia de una cifra importante de sublevados ante Barcelona: AHN Estado, 264 72, Velasco a Grimaldo, 1/IX/1705: «ni hay tales 6.000 hombres, ni aunque fueran $12.000 \mathrm{y}$ se ardiese la ciudad por mar y por tierra, era imposible, según las disposiciones dadas y su natural cobardía, que lograsen su intento». 
asedio y asalto directo de Barcelona, ni para rodearla. En esto se muestran de acuerdo Velasco, los generales aliados, la prensa inglesa y la simple lógica militar.

Se abre por tanto un periodo de tensa espera, en el que ninguna de las partes toma la iniciativa. No lo hacen los aliados e, inexplicablemente, no lo hace Velasco. Los combates en el Principado no se limitaban a Barcelona. Abierta la insurrección en Vic se habían sucedido distintos pronunciamientos por toda Cataluña, directamente relacionados con la presencia de grupos armados ${ }^{59}$. Los vigatans se mostraban activos especialmente en dos zonas: Lérida y Tarragona. Por su proximidad a Fraga, Lérida era una preocupación evidente para el virrey y arzobispo de Zaragoza, Antonio Ibáñez de la Riva, quien trata de ayudar en su defensa y mantiene una frecuente correspondencia con el obispo y el veguer leridanos. Desde Fraga se escribe al arzobispo el 23 de septiembre, preocupados por la situación «cobran más alas los sediciosos y los nuestros pierden el brío, y más estándose tan quieto don Francisco de Velasco con toda su caballería dentro de Barcelona ${ }^{60}$.

En el campo de Tarragona los hermanos Nebot capturan su villa natal, Riudoms, según escribe Velasco el 31 de agosto ${ }^{61}$. Bajo amenaza, habían forzado a los jurados a aclamar al archiduque. Después hicieron lo propio con la localidad próxima de Mont-roig. Enterados, los comandantes de Tarragona realizan una salida para capturar a los hermanos o recuperar la plaza por sorpresa. Los insurrectos, parapetados, rechazan a la partida con descargas de fusilería. Velasco escribe «les he desaprobado esta acción por imprudente (aunque valerosa)».

Debemos de tener en cuenta que el virrey era la máxima autoridad militar en el Principado. Estos dos apuntes resumen perfectamente cuál fue su táctica en la defensa: no hacer nada, patente en su carta anterior:

aunque generalmente toda Cataluña faltase a la obediencia que debe a SM, conservando a Barz ${ }^{\text {na. }}$ como lo está y estará siempre que se halle tan prevenida de todo, como lo queda ahora, lo demás importa nada ${ }^{62}$.

59 Sobre como cristaliza la revuelta en Vic, PÉREZ APARICIO, 1993, vol.28: 365-366. Para el contexto en el Principado, TORRAS I RIBÉ, 1 (Barcelona, 1983): 191, «en aquest cas dificilment es pot parlar del decantament catala a favor de 1'Arxiduc com d'una, reacció espontania i generalitzada com la que es va produir l'any 1640, i aquest contrast també el podem veure palesat en nombrosos exemples si analitzem l'actuació dels diversos municipis del país en el moment del capgirament catala».

60 AHN Estado, 264. El gobernador de Fraga al arzobispo de Zaragoza, 23/IX/1705.

61 AHN Estado, 264 72. Velasco a Grimaldo, 31/VIII/1705.

62 AHN Estado, 264, 72 y también 264, Velasco a Grimaldo, 5/IX/1705, «con lo que hoy engañan más a el archiduque y a los Aliados es con las obediencias que violentamente van sacando los amotinados del País de diferentes lugares incapaces de resistirse en que fundan un 
Esto resultaba discutible: renunciaba a su principal baza militar que era su superioridad en caballería. La hubiera podido utilizar para hostigar a los aliados, cortando sus líneas de suministros, impedir que los rebeldes siguieran tomando más plazas o, quizá la mejor opción, acudir en la defensa de Lérida y mantener abierta la ruta con Aragón, amenazada por los rebeldes. Con su infantería hubiera bastado para defender Barcelona, que no estaba siendo atacada. Es más, con su actitud daba argumentos al enemigo. Él mismo lo pone de manifiesto:

Han dicho algunos desertores quería el Príncipe de Darmestat acreditar la impostura de lo débil de esta guarnición haciéndola el cargo de que no se hacían salidas, siendo así que estando su campo cerca de una legua distante de la Plaza y retirándose a el precipitadamente sus guardias avanzadas cuando ven que cuatro caballos nuestros se acercan más de lo ordinario, como había de llegar el caso de estas pretendidas salidas, pero si se acercan ya tendrán lo que desean ${ }^{63}$.

Velasco empleó su caballería en la ciudad para realizar patrullas nocturnas. Rechaza repetidamente las ofertas de formar la Coronela, y el 5 de septiembre prohíbe las rondas nocturnas de las escuadras, sustituyéndolas por sus tropas $^{64}$. Otras decisiones son también dudosas. Desde el principio toma la política de dejar salir a los que quieran para, según escribe a Madrid, librar Barcelona de enemigos ${ }^{65}$. Establece un toque de queda nocturno, bajo pena de

gran capital diciendo que el archiduque es ya Rey de mucha parte de Cataluña, como sin siéndolo de Barcelona, importase algo que pusiese a su obediencia todo lo restante de la provincia».

63 AHN Estado, 264, 264, Velasco a Grimaldo, 05/IX/1705.

64 AHN Estado, 264 «Por lo que toca a la quietud de esta ciudad esta tan asegurada, que a las nueve de la noche, no se halla en las calles otra gente que las de las rondas, y como los concelleres ocupaban en las que se hacen por su parte hasta 200 hombres de todos los estamentos y yo haya considerado ya inútil esta providencia, los he mandado excusen este trabajo a su gente, que para evitar cualquier inquietud, basta la caballería y la infantería que únicamente tengo destinada a ese fin».

${ }_{65}$ AHCB CC, fols. 285-287, junta del 5/IX/1705. AHN Estado, 264. Velasco a Grimaldo, 31/VIII/1705. «Cada día se va limpiando más esta ciudad de la gente de quien se podía tener alguna sospecha porque en termino de pocas horas se les manda salir de ella, dejando al arbitrio de los que se echan que vayan a servir de Auxiliares a los Aliados y aunque es infinita la gente que antes del arribo de las Armadas había salido de $\mathrm{Bar}^{\text {zna }}$, unos por el miedo de las bombas, y otros por sus bien fundadas desconfianzas de que corrían mayor riesgo en quedarse dentro, habiendo mandado la semana pasada que no se dejase salir a nadie de aquí, ni entrar a los que no trajesen bastimentos, hice publicar un bando dando licencia que saliesen cuantos quisieran en la inteligencia de que no habían de volver a entrar hasta que se hubiesen retirado las Armadas con sus tropas de desembarco y va saliendo alguna gente, particularmente frailes y clérigos». 
muerte, para las casas próximas a las murallas ${ }^{66}$. El día 10 pide el establecimiento de una carnicería exclusivamente para los oficiales, ante la escasez, a lo que se aviene la ciudad ${ }^{67}$.

Mientras, el Consell del Cent se mantiene en un apoyo constate. El 31 de agosto, ante los esfuerzos de las tropas, se aprueba una subvención diaria para su mantenimiento, la «olla de la guarnición» ${ }^{68}$. El 3 de septiembre habilita a la Novena de Guerra para requisar los víveres que se encuentren, ofreciendo el 4 al virrey la subvención y la asistencia a los soldados ${ }^{69}$. El día 14 envía una felicitación por la defensa de un ataque y aprueba el envío de pan y aguardiente a la guarnición de la fortaleza. Ya con Montjuic en poder aliado el 23 entrega, a requerimiento de Velasco, 16.500 libras del donativo voluntario aprobado en las Cortes de 1702 al pagador de las tropas reales ${ }^{70}$. Ésta es la tónica del comportamiento del Consell durante el asedio. El propio Velasco reconoce dicha predisposición:

Los caballeros Catalanes que han quedado dentro de Bar $^{\text {zna }}$. (que son muchos y de la primera posición del Principado) me asisten con toda atención e igual deseo de sacrificar sus vidas y haz ${ }^{\text {das }}$ en $\operatorname{Serv}^{\mathrm{o}}$ del Rey $\mathrm{N}^{\mathrm{o}} \mathrm{S}^{\mathrm{r}}$ y con correspondiente fineza se muestran para cuanto se ofrece la Ciudad y el Consistorio de la Diputación, y muchos caballeros de los que están en diferentes partes del País, como también las ciudades q. como en otras ocasiones he dicho a VS, aunque en todas partes hay algunos mal inclinados, los comunes por lo general están firmes en no faltar a su primera obligación ${ }^{71}$.

Entretanto, los aliados no toman ninguna iniciativa. Salvo esperar y ver si se producía el levantamiento. Excavan trincheras, fortifican su campo y construyen un baluarte artillado en la ribera del Besós desde donde cubrir una eventual retirada. Celebran consejos de guerra en el Britannia los días 27 de agosto y 2,5 y 8 de septiembre ${ }^{72}$. Su análisis es que carecen de fuerza suficiente para un asalto, son escépticos respecto de un alzamiento catalán antes de la caída de Barcelona, y de que ésta se produzca sin aquél. Son reiteradas las alusiones a lo avanzado de la estación, por los peligros para la navegación, y, además,

the Garrison may be considerable reinforced, both from Madrid where we Know they have a thousand or twelve hundred horses, and from the frontiers of

66 AHCB CC, fols. 285-287, junta del 5/IX/1705.

67 AHCB CC, fols. 290-291, junta del 10/X/1705.

68 AHCB CC, fols. 280-281, junta del 31/VIII/1705.

69 AHCB CC, fols. 282-283, junta del 3/9/1705. Folios 283-285, junta del 4/IX/1705.

70 AHCB CC, fols. 297-300, junta del 23/IX/1705.

71 AHN Estado, 264, Velasco a Grimaldo, 31/VIII/1705.

72 TNA SP 94/75. 
France, which are but 35 leagues distance, and it is well Known that an Army five times as Strong as ours could not to be sufficient to quest the round and to prevent succours going in ${ }^{73}$.

Un peligro que parece probable, algunas noticias informaban de que Berwick había recibido orden de dirigirse a Barcelona con tres regimientos de dragones y seis batallones de infantería desde la Provenza ${ }^{74}$. El tiempo corría claramente en contra de los aliados. Entre ellos se forman dos bloques. De una parte Schratenbach, Gorge, Shannon, Hamilton, Wills, y Charlemont son partidarios de levantar el sitio para evitar el riego de destrucción del ejército y navegar en ayuda del duque de Saboya. Representan lo que se puede calificar de lógica militar. La división se explicita en la votación del día $8^{75}$. A requerimiento del archiduque se propone continuar en el empeño durante dieciocho días. Todos los antedichos expresan su voto negativo y su opción por levantar el campo. Con lógica política, Peterborough, Darmstadt y Stanhope votan a favor e imponen su decisión.

Pero es necesario un plan y surge el proyecto de realizar un ataque por sorpresa, con un número limitado de tropas, a la fortaleza de Montjuic, para intentar su captura y, con ésta, un elemento que consiga decantar la situación. Vaya por delante que lo sorpresivo del ataque debe ser relativizado. El 5 de septiembre, Velasco había escrito comunicando un plan contra el cual tenía fuerzas para oponerse:

Los desertores que hasta hoy han entrado en esta Plaza (...); entre ellos vino dos días ha uno de muy buena razón, y este oyó a sus oficiales había habido un gran debate entre Milor Peterbour, y el Príncipe de Darmestat sobre que el primero decía que no han habiendo hallado nada de lo que le habían ofrecido, quería volver a embarcar sus tropas, sobre que el Príncipe se ofreció a que con cuatro batallones que le diesen, y la gente del país tomaría a Monjuy, y que después llenando los fosos de la plaza de fajina y arrimando escalas la tomaría; la lastima es que los generales de los aliados tengan el juicio mas en su lugar que Darmestat, porque si los cascos de todos fueran tan ligeros que conviniesen de emprender estas dos operaciones no serían muchos los que volviesen a embarcarse ${ }^{76}$.

73 El progresivo deterioro del tiempo encuentra su confirmación en la correspondencia del Virrey: «El tiempo ha empezado a ponerse poco a propósito para subsistir muchos días en la mar, porque la noche pasada y todo el día de hoy, ha corrido un viento muy recio y frio, y el semblante no es de proseguir más favorable» AHN Estado, 264, Velasco a Grimaldo, 05/09/1705.TNA SP 94/75, consejo de guerra en el Britannia, 27/VIII/1705 (N.S.).

${ }^{74}$ Daily Courant, 7/IX/1705, $\mathrm{n}^{\circ}$ 1061, citando la Leiden Gazette sobre noticia fechada en Montpelier de 21/VIII/1705. También en Daily Courant 21/IX/1705, n ${ }^{\circ} 1073$, fechada el 18/IX en Paris.

75 TNA SP 94/75, consejo de guerra en el Britannia, 8/IX/1705 (N.S.).

76 AHN Estado, 264, Velasco a Grimaldo, 05/IX/1705. 
Disponemos de varias versiones sobre el asalto a Montjuic ${ }^{77}$. No hay demasiadas discrepancias entre ellas. Varían algo las cifras y algún detalle anecdótico cómo, por ejemplo, el alcance y secuencia de las heridas de Darmstadt. La mayor incógnita es saber quién fue el autor intelectual del plan de asalto, Peterborough o el príncipe, pero ni en las fuentes tratadas, ni en los consejos de guerra, aparece. Desde luego lo que no se sostiene es la afirmación de San Felipe de que se trataba de una operación de Darmstadt marginando al inglés, ya que en todas las fuentes consta su participación ${ }^{78}$.

El ataque se produjo en la madrugada del 17 de septiembre, con un contingente reducido de tropas, unos 1800 infantes y 300 caballos. Previamente Peterborough había ordenado simular el reembarco de la artillería y el levantamiento del campo. La columna avanzó por Sarriá y Gracia hasta situarse en Sans, desde donde comienza el ataque, mandando el Príncipe la vanguardia, cubierta su retaguardia por el conde inglés. Comienza a escalar por el foso y murallas. Este primer ataque consigue ganar y controlar la obra exterior, donde se capturan varias piezas de artillería. También Darmstadt resulta muerto en un confuso episodio. En poder español queda el castillo principal, con su guarnición napolitana. Una salida desde Barcelona es rechazada por Peterborough.

Los aliados empezaron a bombardear la posición de los napolitanos. El día 27 un proyectil acierta en la santabárbara, provocando la deflagración de la pólvora almacenada. En la explosión se produce la muerte del comandante y de gran parte de los defensores y la captura total de Montjuic, desde donde comienzan a bombardear la ciudad, apoyados por la flota.

77 Quizá la relación más interesante, y que hemos seguido, sea la contenida en AHN Estado, 264 «Notizias del campo real sobre Bar $^{\text {na }}$ desde el dia 17 de $S^{\text {bre }}$ de $1705 »$. A pesar de encontrarse entre la documentación borbónica de la guerra, parece más tratarse de una relación interceptada por Velasco y remitida a Madrid ya que termina con «y se espera en breve el rendimiento de la plaza» y la apostilla «En eso ultimo mienten y es relación de rebeldes» realizada con tinta distinta y la caligrafía de las cartas de Velasco. En AHN Estado 264 hay otra relación, anónima y sin fechar, anterior a la toma completa de Montjuic, posiblemente reenviada por el arzobispo de Zaragoza a Grimaldo con 264/35, 27/IX/1705 y traspapelada. La prensa también recogió las peripecias del asalto, London Gazette, 24/IX/1705, $\mathrm{n}^{\circ} 4161$; London Gazette, 27/IX/1705, no 4162; Post Man, 29/IX/1705, no 1450; Daily Courant, 5/X/1705, nº 1085; Daily Courant, 6/X/1705; Observator, 6/X/1705, $\mathrm{n}^{\circ}$ 55. Las relaciones en fuentes secundarias son abundantes, señalaremos las más completas: ALCALÁ GALIANO, 1844, V: 194-199; VOLTES BOU, 1963, II: 46-58; TORRAS y RIBÉ, 1999:122-136, y la más reciente, SEGURA GARCÍA, 782 (Madrid, 2006):89-96.

78 «Peterbourgh, antes de saber la muerte de Armestad, viendo la infelicidad de la primera empresa , y queriendo perder al Príncipe , por envidia de la dirección que se le había encargado, repugnando trabajar para construir ajena gloria , mandó embarcar todas las Provisiones, Armas, y Pertrechos, y que se volviese al Navío el Rey Carlos , para atribuir la desgracia al Príncipe , no habiendo sido jamás de su aprobación la empresa de Barcelona», BACALLAR y SANNA, 1725, I:227-229, cita en 228. 
Pocos días después, el 4 de octubre, Velasco se dirige al Consell del Cent:

Habiendo llegado ya el caso en que es preciso entender en la capitulación de esta Plaza, me ha parecido indispensable en la obligación de mis cargos participarlo a VE para que en su inteligencia discurrirá lo que Juzgare de su mayor consuelo y conveniencia hacia sus intereses, proponiéndomelo con la mayor brevedad posible; porque para la formación de los artículos se ha de tener presente ${ }^{79}$.

Los aliados aceptaran las capitulaciones presentadas por el virrey, y el día 9 se concierta la entrega para el día $14^{80}$. Es entonces cuando se produce el levantamiento popular, instado por rumores acerca de los pretendidos planes de Velasco de llevarse a los prisioneros. La situación se complica con combates callejeros, pillajes y saqueos. Ante este escenario, los aliados entran en la ciudad para ocupar las murallas y el Común establece patrullas por las calles, dictando órdenes de que la población permaneciera en sus casas. Tras unos días, se produce la entrada triunfal del archiduque, el día 7 de noviembre.

\section{Velasco en CATALUÑa}

Las evidencias apuntan a que, cómo poco, Velasco padecía algún tipo de prejuicio contra los catalanes. Esto, que ha sido recogido frecuentemente por la historiografía e incluso por la prensa coetánea, influyó de manera determinante en nuestra opinión, en el desenlace del asedio, e impregna y se explicita en su correspondencia con Madrid ${ }^{81}$.

En sus cartas previene a la Corte de la escasa confianza que se debe tener en su fidelidad: «la obstinada infidelidad de estos naturales» ${ }^{82}$, o que «y cada día se aumentan los justos recelos con que se debe vivir de esta depravada nación» ${ }^{83}$. Pero también incluye juicios de valor sobre sobre su carácter y las virtudes que los adornaban. Así escribe sobre «esta canalla del País» ${ }^{84}$ y de «su natural cobardía» ${ }^{85}$. Expresa su confianza en «que la experiencia acabe de poner a los Aliados en conocim $^{\text {to }}$ de los embustes de los Catalanes y delo q.

79 AHCB CC, fol. 302, 4/X/1705.

80 TNA SP 94/75, consejo de guerra en el campo delante de Barcelona, 8/X/1705 (N.S.). Copia de las capitulaciones solicitadas por Velasco en BL 1445/17(12) 1705.

81 VOLTES BOU 1963:8-11, ALBAREDA, 1993: 127-132. Para la referencia sobre la prensa, "The Governour of Barcelona has promissed to make a vigorous defence, but as he suspects the Fidelity of the Inhabitantants, 'tis said he has been order'd to disarm them upon the approach of the allies", The Post Man, 4/IX/1705, nº 1443.

82 AHN Estado, 272. Velasco a Ribas, 28/I/1705.

83 AHN Estado, 272, Velasco a Ribas, 15/I/1705.

84 AHN Estado, 264, Velasco a Grimaldo 05/IX/1705.

85 AHN Estado, 264/72, Velasco a Grimaldo 1/IX/1705. 
deben fiar de sus ofrezim $\left.{ }^{\text {tos }}\right\rangle^{86}$, o concluye que «de aquí se saca la evidencia que los Catalanes son más bárbaros que los herejes y que todas las naciones bárbaras del mundo» ${ }^{87}$. Resulta difícil imaginar que tales juicios y opiniones quedasen totalmente velados al pueblo sobre el que tenía encomendado el gobierno o que se contribuyera así a reforzar su lealtad ${ }^{88}$.

Aunque, sin lugar a dudas, Velasco lograba cotas realmente singulares en su carta del 5 de septiembre a Grimaldo:

Por un sujeto que vino esta mañana del campo del enemigo, he sabido que los Catalanes empezaban ya a murmurar de que los Aliados querían abandonarlos, y que decían se habían de echar sobre ellos, en cuyo caso tuvieran los Aliados quien los defendiese, porque yo había de echar 500 caballos con otros tantos granaderos a la grupa para acabar con esta canalla, aunque ella es incapaz de ejecutar cosa de resolución, y tanto que aun estando del abrigo del ex ${ }^{\text {to }}$ desembarcado, se retiran todos a lo mas alto de las montañas sin atreverse ninguno a dormir en el campo del enemigo ${ }^{89}$.

Detengámonos un momento en la ocurrencia del virrey. Está dispuesto, por fin, a realizar una salida, pero en defensa las tropas de unas potencias que están en guerra con su rey e invadiendo sus dominios y hacerlo atacando a unos hombres que, sediciosos o no, eran, por derecho, vasallos de su señor. En caso de éxito, garantizaría el reembarco de unos enemigos que así podrían volver a atacar. El delirio de Velasco parece alcanzar unas dimensiones inexploradas. Podríamos especular sobre que hubiera hecho efectivamente en el caso de presentarse tal contingencia, pero el simple hecho de incluirlo en una carta a Madrid demuestra una total y absoluta falta de criterio. Fatal, si tenemos en cuanta su responsabilidad y misión.

En realidad este episodio y los antecedentes prueban la confusión en la que parecía vivir. Durante todo el asedio se comportó como si su misión principal hubiese sido el evitar a toda costa un levantamiento de Barcelona, olvidándose, aparentemente, del ejército enemigo a sus puertas y de los súbditos a su cuidado. Además de suponer su dejación de la iniciativa, cediéndola fatalmente a los aliados: su renuncia a atacar mediante salidas desde Barcelona parece estar más orientada a tener sus tropas reunidas y vigilando estrechamente al que le parecía su enemigo a batir, los catalanes.

Sus errores directos fueron fatales. Sabiendo y habiendo comunicado a Madrid la existencia de un plan para realizar un ataque por sorpresa a Mont-

86 AHN Estado, 264/72, Velasco a Grimaldo 1/IX/1705.

87 AHN Estado, 264, Velasco a Grimaldo, 31/VIII/1705.

88 Parecida es la opinión de FERNÁNDEZ ALBADALEJO, 2001: 311: "En la inclinación de los catalanes del año 1705 a favor del archiduque influyeron, sin duda, elementos coyunturales, como los métodos despóticos del virrey Velasco".

89 AHN, 264, Velasco a Grimaldo, 05/IX/1705. 
juic, no toma ninguna prevención al respecto. Pensemos que, empleándose a fondo, hubiera podido infringir fácilmente una dura derrota a los atacantes. Su situación era idónea. El campo enemigo estaba muy lejos, en la parte opuesta de la ciudad. El ataque se produjo tras un gran rodeo a vista de las murallas Barcelona y de Montjuic. Siempre tuvo la superioridad en caballería. Con las tropas que emplearon en el ataque, también en infantería. Y la única artillería que había era la suya, los aliados no la trasladaron consigo en su avance por sorpresa. También resulta dudosa su decisión de rendir la plaza tras la captura de la fortaleza. Ciertamente la situación resultaba más comprometida que hasta entonces, pero aun así hubiera podido tratar de resistir mientras esperaba la llegada de refuerzos y del invierno. Pero decide capitular, prácticamente sin haber luchado en la defensa de su capital.

Y ¿cuál era la opinión de las autoridades de Madrid acerca de la actuación de su virrey de Cataluña? La clave para responder a esta pregunta se encuentra en una carta remitida el 27 de septiembre al arzobispo de Zaragoza. La misma transmite que, ante el estado de cosas en Barcelona, y dado que «Don Francisco de Velasco no ha podido reprimir su orgullo», además de lo que convenía unificar bajo un solo mando las operaciones militares en los territorios de la Corona de Aragón, Felipe V había decidido nombrar teniente general al mando al príncipe T'Serclaes de Tilly, fijando sus competencias «a las disposiciones de la Guerra y todo lo incidente de ellas»» ${ }^{90}$.

Llegó tarde el nombramiento, la batalla ya estaba perdida. Pero resulta muy significativo, su redacción y contenido implicaban una grave censura de la actuación de Velasco ${ }^{91}$. Éste no parecía gozar de la idoneidad necesaria para un puesto tan crítico. Tilly, sin embargo, sí que tenía un peso mucho mayor, como lo habría de demostrar al ser nombrado, meses más tarde, para otro puesto sensible, el de virrey de Navarra tras la pérdida de Aragón.

\section{CONCLUSIONES}

Es posible señalar la existencia de un sustrato levantisco en Cataluña. El XVII es un siglo de fuerte agitación social y las rebeliones, con carácter político o no, marcan su cronografía ${ }^{92}$. Por tanto podemos hablar de un país in-

90 AHN Estado, 264/28, Grimaldo al arzobispo de Zaragoza, 27/IX/1705.

91 Al quitarle la jefatura militar le privaban de su principal competencia. Sobre este tema ver DE CASTRO, 2004: 122. La autora afirma que los informes de Velasco «no brillan por su coherencia». Sitúa el ataque aliado justo a los tres meses de la reorganización de las secretarias y con Grimaldo recién nombrado, lo que quizá explique su continuidad.

92 La guerra de Els Segadors o la Revuelta de las Barretinas son sólo dos episodios de este XVII turbulento, a este respecto, ver GARCÍA CÁRCEL, 20 (Valencia, 1994):47-66. 
flamable en el que cualquier chispa podría prender. Sin embargo, no puede hablarse de una insurrección generalizada, ni aun mayoritaria, de los catalanes en favor del pretendiente, ya que su aceptación global no se produjo hasta después de la capitulación, por lo que esta sería la causa, no la consecuencia, del reconocimiento del archiduque. Además de las afirmaciones en dicho sentido en la correspondencia de las autoridades de la Corona, contamos con dos elementos más de convicción: el registro de deliberaciones del Consell del Cent, que es claro respecto de la colaboración que prestaron en todo momento en la defensa de la ciudad - incluso con los aliados ya en Montjuic - y, sobre todo, las quejas sobre la actitud de los catalanes en los consejos de guerra aliados que manifiestan claramente no haber encontrado el recibimiento esperado.

Entonces ¿cuáles fueron las causas de la pérdida? En nuestra opinión, la combinación de varios elementos. Por una parte no debemos de olvidar la importancia del azar en el devenir histórico. Efectivamente, los aliados, después de sopesar otras alternativas, inician una empresa para la que carecen de tropas suficientes. Recordemos que al año siguiente un ejército tres veces superior bajo el mando de Felipe $\mathrm{V}$ fracasa en su intento de reconquistar la ciudad. Ante dicha situación, intentan una operación de alto riesgo y por sorpresa que consigue un éxito sólo parcial, ya que no logra capturar la totalidad de Montjuic. En ese momento, en vez de tener que enfrentarse a un contraataque que no se produce, habrían de gozar un disparo afortunado que les proporcionaría la totalidad de la fortaleza. Podemos afirmar que una concatenación de circunstancias venturosas llevó a los aliados a tomar Barcelona. Por otra parte, la completa incompetencia del virrey Velasco, quien hizo dejación de su responsabilidad de defender la plaza, Cataluña y sus habitantes, transmutándola en su vigilancia y aún persecución, en lo que parece más tratarse de una obsesión personal que de un comportamiento racional. Esta actitud le impulsó a una sucesión de errores que llevarían a un completo fracaso. Incompetencia o suerte, lo cierto es que, con la capitulación de Barcelona de 1705 , se habría de cambiar el rumbo de la guerra y, en buena medida, de la propia Historia de España.

\section{BibliOgRAFÍA}

Albareda Salvadó, Joaquim, Els Catalans i Felip V, de la conspiració a la revolta (1700-1705), Barcelona, Vicens Vives, 1993.

Albareda Salvadó, Joaquim, «L'austriacisme, una visió alternativa: del projecte de 1705 a l'exili», Barcelona Quaderns d'Història, 7 (Barcelona, 2002): 23-50.

Albareda Salvadó, Joaquim, La Guerra de Sucesión de España (1700-1714), Barcelona, Crítica, 2010.

Alabrús i Iglésies, Rosa María, Felip Vi l'opinió dels catalans, Lleida, Pages, 2001. 
Alcalá Galiano, Antonio, Historia de España, Tomo V, Madrid, Imprenta de la Sociedad Literaria y Topográfica, 1844.

Arrieta, Jon, «Austracismo, ¿Qué hay detrás de nombre?», Los Borbones: dinastía y memoria de nación en la España del siglo XVIII, Madrid, Marcial Pons, 2002; 177-216.

Arrieta, Jon, «Conversaciones con Ernest Lluch acerca del Austracismo», Eliseo Martín (ed.), Felipe Vy su tiempo, Zaragoza, CSIC, 2004; 235-256.

Clode, Charles, The military forces of the crown: their administration and government, vol. 2, Londres, John Murray, 1869.

De Bacallar y Sanna, Vicente, Comentarios de la guerra de España e historia de su rey Phelipe V el Animoso, vol. I, Génova, Matheo Garviza, 1725.

De Castro, Concepción, A la sombra de Felipe V: José de Grimaldo, ministro responsable (1703-1726), Madrid, Marcial Pons, 2004.

Downie, Alan J., «The Commission of Public Accounts and the Formation of the Country Party», The English Historical Review, 91/358 (Londres, 1976): 33-51.

Fernández Albadalejo, Pablo, Los Borbones: dinastía y memoria de nación en la España del siglo XVIII, Madrid, Marcial Pons, 2001.

García-Badell Arias, Luis M., «Los primeros pasos de Felipe V en España: Los deseos, los recelos y las primeras tensiones», Cuadernos de Historia del Derecho, 15 (Madrid, 2008); 45-127.

García Cárcel, Ricardo (ed.), De los elogios a Felipe V, Madrid, Centro de Estudios Políticos y Constitucionales, 2004.

García Cárcel, Ricardo, «Historia social e historia nacional: algunas reflexiones sobre la historiografía de las revueltas en la Cataluña moderna», Historia Social, 20 (Valencia, 1994): 47-66.

García Espuche, Alberto, «Transformació econòmica i sistema urbà: Catalunya 15501640», Manuscrits: Revista d'història moderna, 15 (Barcelona, 1997): 279-302.

García Fuertes, Gemma, «De la conspiración austracista a la integración a la nueva planta: La familia Duran, máximo exponente de la burguesía mercantil en el siglo XVIII», Espacio, Tiempo y Forma, 4/17, (Madrid, 2004): 143-162.

González Camaño, Oscar, «El partit austriacista: coherència, divergència i supervivència d'una facció de poder», Pedralbes, 23 (Barcelona, 2003): 295-324.

Hattendorf, John Brewster, «English Grand Strategy and the Blenheim Campaign of 1704», The International History Review, 5/1 (Londres, 1983): 3-19.

León Sanz, Virginia, Entre Austrias y Borbones. El archiduque Carlos y la monarquía de España, Madrid, Sigilo, 2009

León Sanz, Virginia, Carlos VI. El emperador que no pudo ser rey de España. Madrid, Aguilar, 2003.

León Sanz, Virginia, y Sánchez Belén, Juan A., «Confiscación de bienes y represión borbónica en la Corona de Castilla a comienzos del siglo XVIII», en Cuadernos de historia moderna, 21, (Madrid, 1998): 127-175. 
Martí, Eduard, La conferencia de los Tres Comunes (1697-1714), Barcelona, Milenio, 2008.

Martínez Ruiz, José I., «De Tánger a Gibraltar: el estrecho en la praxis comercial e imperial británica (1661-1776)», Hispania, 65/221, (Madrid, 2005): 1043-1062.

Pérez Aparicio, María del Carmen, «La guerra de Sucesión en España», Jover Zamora (dir.), Historia de España Ramón Menéndez Pidal, 28, Madrid, Espasa-Calpe, 1993: 303-501.

Ragon i Cardoner, Joaquim, «El último virrey de la administración habsburguesa en Cataluña: Jorge de Darmstadt y landgrave de Hassia, (1698-1701)», Pedralbes, 2 (Barcelona, 1984): 263-271.

Rubini, Dennis, "Politics and the Battle for the Banks, 1688-1697", The English Historical Review, vol. 85/337 (Londres, 1970): 693-714.

Segura García, Germán, «La toma de Barcelona por el archiduque Carlos (1705): un episodio relevante en la Guerra de Sucesión», en Ejército, 782, (Madrid, 2006): 89-96.

Torras i Ribé, Josep María, «El princep Jordi de Darmstad i la conspiració austriacista de Catalunya (1697-1705)», L' Avenç: Revista de història i cultura, 264 (Barcelona, 2001): 23-31.

Torras i Ribé, Josep M., «Reflexions sobre l'actitud des pobles i estaments Catalans durant la guerra de Successio», Pedralbes, 1 (Barcelona, 1983): 187-210.

Torras i Ribé, Josep M., La guerra de Successió i els setges de Barcelona (16971714), Barcelona, Rafael Dalmau, 1999.

Valls Junyent, Francesc, El paper de les exportacions vitícoles en la configuració de les relacions exteriors de l'economia catalana, 1672-1869, tesis doctoral, (Departament d'Història i Institucions Econòmiques, Universitat de Barcelona), 2001.

Voltes Bou, Pedro, Barcelona durante el gobierno del archiduque Carlos de Austria, 1705-1714, vol. II, Barcelona, Instituto Municipal de Historia, 1963.

Recibido: 27/12/2011

Aprobado: 21/12/2012

Hispania, 2014, vol. LXXIV, nº. 246, enero-abril, págs. 69-94, ISSN: 0018-2141, e-ISSN: 1988-8368, doi: 10.3989/hispania.2014.003 